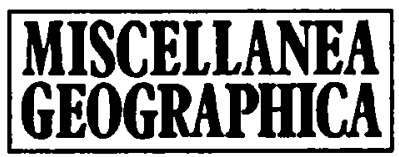

WARSZA WA 1994 Vol. 6

Maksymilian Skotnicki

\title{
LAND UTILIZATION IN THE FARAFRA OASIS
}

Grounds which could be regarded as traditionally cultivable land slope from the built up area westwards in the direction of the fields under reclamation by the governmental agencies. The new works undertaken with the use of considerable amount of means and labour are at different stages of realization, which is apparent from deep tracts of drain pipes set in the north-south direction and geometrically shaped fields stretching outside of them, lying amidst vast expanses of land still unreclaimed. The reclaimed lands range from parcels showing miserable grain cultures on saline soils and fields usually barren of trees but surprising by diversity of their cereals and vegetables, to larger areas in which cereal and fodder crops predominate.

The principal productive area is a fruit-tree grove semi-circling the settlement on the western side. This intensively cultivated area of about 80 hectares is irrigated by a simple gravitation method by two sources of water (Fig.1). The old one, Ain al-Balad (Source of the Town), whose history probably goes as far back as the Roman times, yields ca 500 cubic metres daily and feeds medium-sized parcels where water flows in earthen canals not longer than $250 \mathrm{~m}$. Water distribution does not show a consistent system of organization. It just seeps through crumbling embankments and fills shallow internal pools where usually grow several dozen years old olive trees and date palms (Fig. 2). They do not seem to be carefully tended and are visited only at the time of gathering the crops. On the whole, the system looks markedly neglected. The new welt - a typical bir - drilled in the 1960 s with a capacity of ca 7,000 cubic metres per day is a basic spring. Its water is distributed in the northern and southern, but particularly in the western direction by the canals in their initial parts built of concrete, and farther on just made of earth. From the main ones there branch the secondary canals feeding with water canals on the lower level or directly watering the fields. Within the boundaries of the traditionally cultivable land the network of canals of primary and secondary level exceeds 27 kilometres in length and extends far beyond these old fields into the newly reclaimed lands. Temperature at the mouth of the new well equals $37^{\circ} \mathrm{C} ; 300 \mathrm{~m}$ farther it drops to $31^{\circ} \mathrm{C}$ and at the outlets to the most distant fields to about 


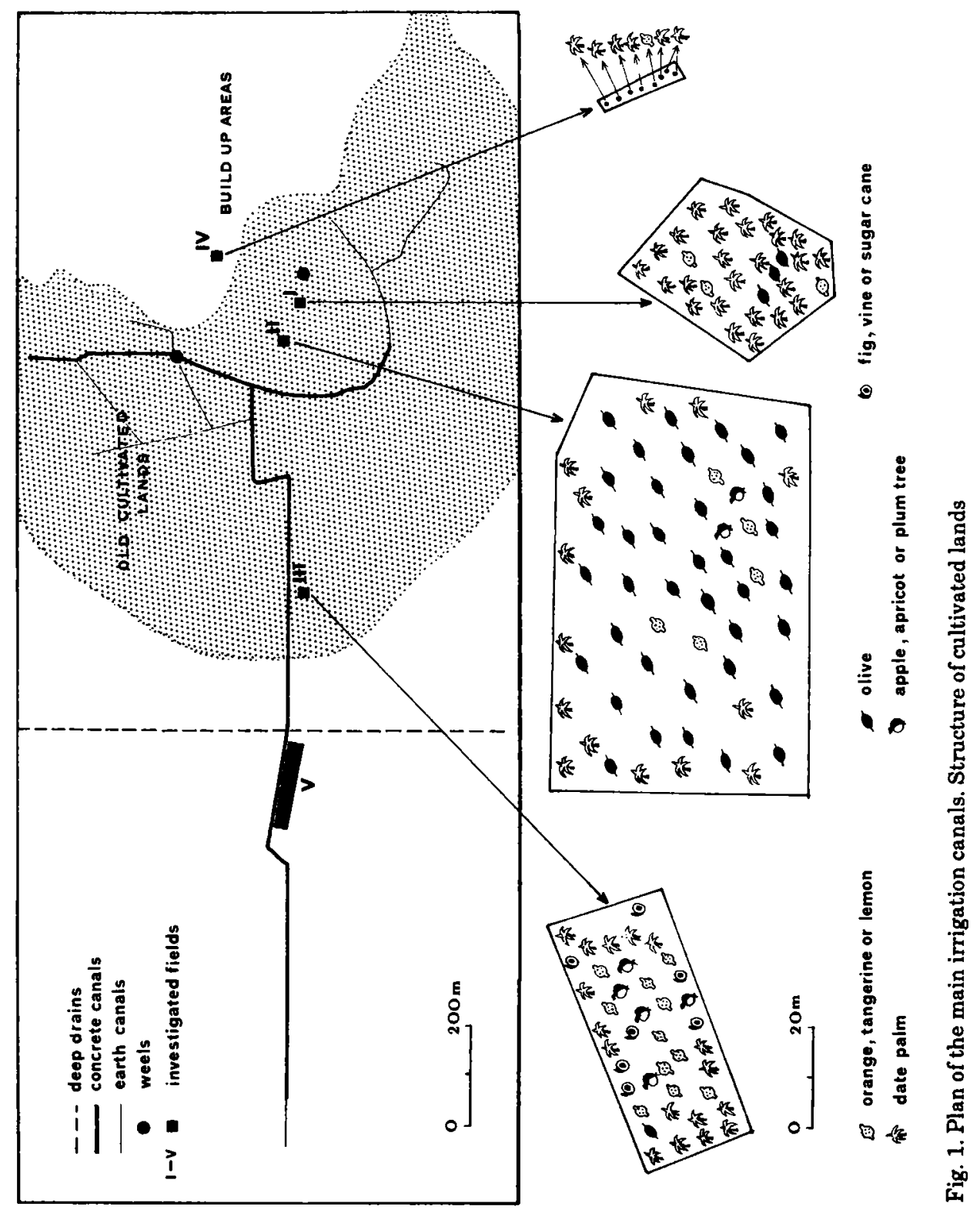




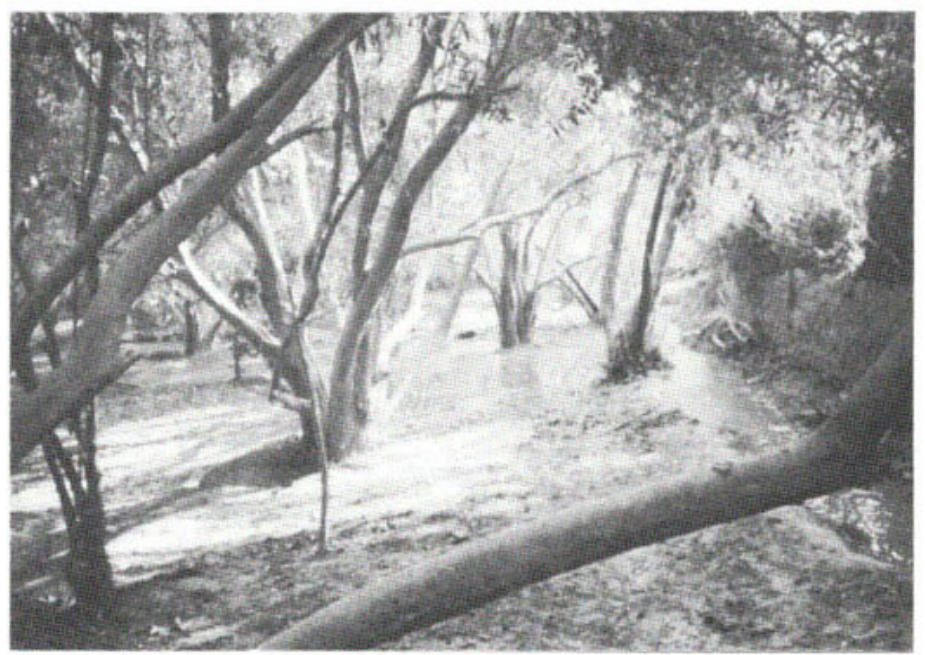

Fig. 2. Fields in the oldest part of cultivated land

$23^{\circ} \mathrm{C}$. The waters are of bicarbonate-nitrate composition, very slightly acid and with low rate of mineralization. The mineralization decreases slowly as water flows away of its source and it is specially noticeable in the proportion of sodium and potassium (see Table 1). On the contrary, on flooded parcels of the ground being under reclamation the mineralization rapidly increases due to the high level of evaporation. Also the chemical composition alters. The analysis of water taken from shallow inundations at the end of canals (samples taken near the saline residues on the surface)

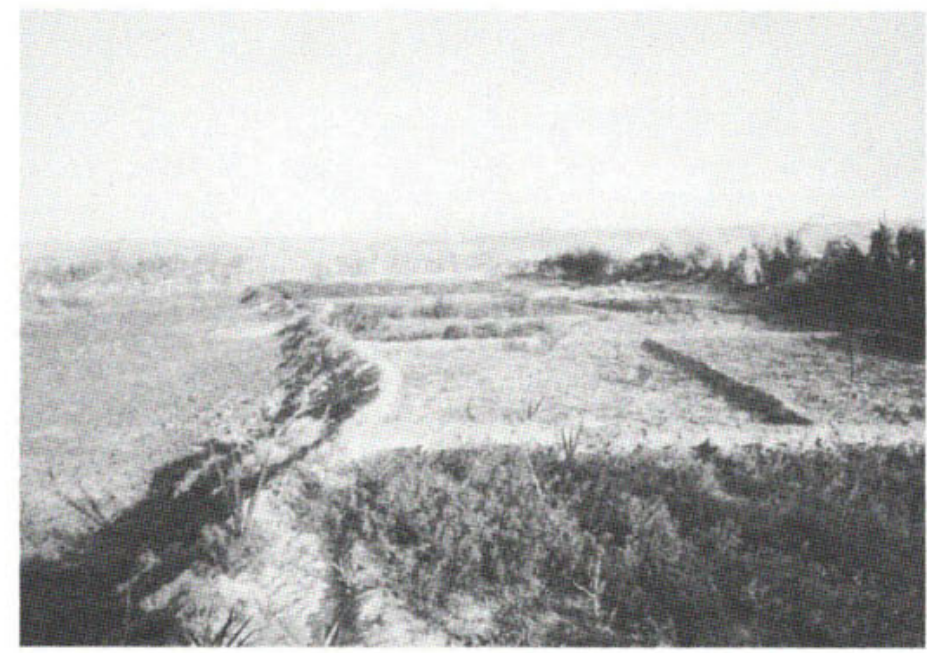

Fig. 3. New fields on the border of the oasis 
demonstrates its great degree of hardness and sulphuric-chloride-sodium components with a significant calcium proportion (see Table 1).

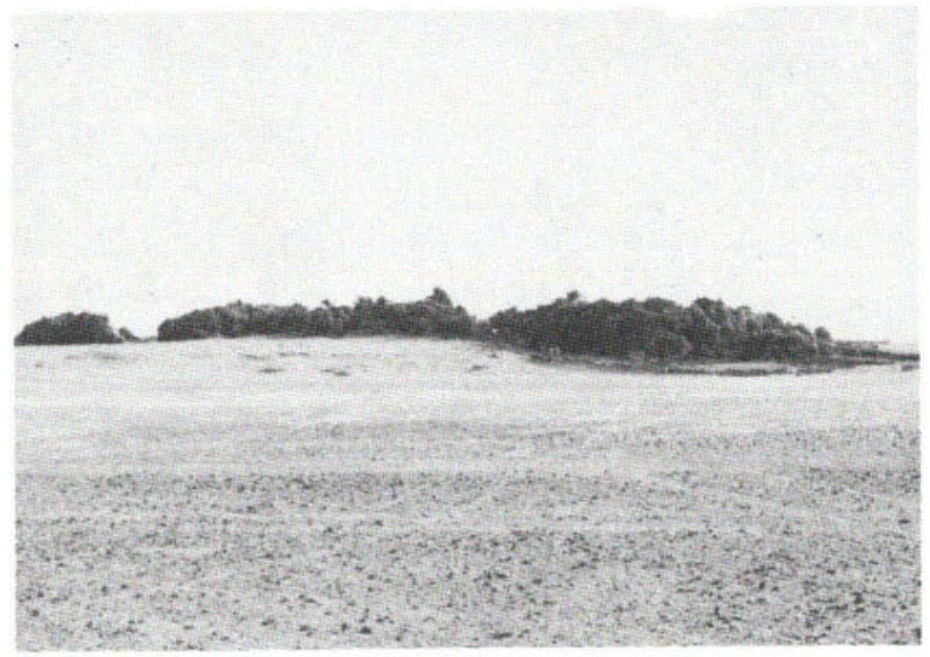

Fig. 4. One of the ain oases

It was hardly possible, because of the limited time and means available, to study in detail the system of the land ownership and particularly the organization of water distribution, except for the information which could hardly be considered to be representative, concerning the time-span attributed to each landholder for watering his canals. In this situation it was

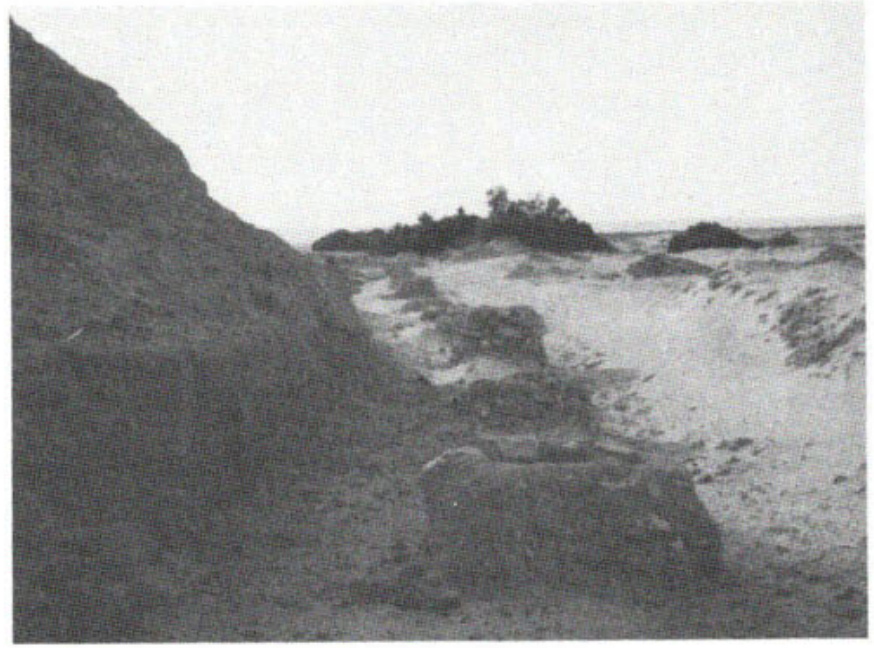

Fig. 5. Qanat leading to Ain Kifirein 
difficult to answer the nearly classic questions which should be asked while studying the land utilization in the oasis, such as whether there exists a hierarchical system of land distribution in connection with the distance from existing water sources and dependent on the social hierarchy of families of land cultivators or chronology of settlement or what is the relation of the area of utilized land and the predominant crops cultivated to the water source; and how the mechanism of water distribution works in detail. First of all, the general impression is that water is in abundance: ca 7,500 cubic metres of regular flow without fluctuation for about 80 ha of cultivated land. The surplus overflows the saline, uncultivated area in the west. Also, before the new well was put into service, the water was abundant although periodically deficit could happen (Fakhry 1974, about the years 1945-62). According to the data of 1962, in the area of Farafra, inclusive of the small external oases with springs (uyun), the daily supply averaged 3,600 cubic metres, i.e. about 10 per cent more than established needs in the period of the highest demand in July (el-Ramly 1964). In such a situation, given the abundance of water, it does not seem that the localization of a field at the first, second, third or fourth level (in relation to the source) could have been significant. Also the relative level of salinity of irrigation water, changing according to the distance from its source, does not seem to be significant (see Table 1). It is then conceivable that today, as well as in the past, there were no conflicts within the rural community connected with the access to water or the location of the fields.

Table 1

Chemical properties of water in the Farafra oasis

\begin{tabular}{|c|c|c|c|c|c|c|c|c|c|c|}
\hline & \multicolumn{8}{|c|}{$\mathrm{mg} / \mathrm{l}$} & \multicolumn{2}{|c|}{${ }^{0} \mathrm{~N}$} \\
\hline & 窝 & స్టూ & $\stackrel{+}{\sum_{i}^{\infty}}$ & \begin{tabular}{l}
+4 \\
\multirow{z}{*}{+4} \\
$z$
\end{tabular} & Tे & '胥 & $\frac{1}{0}$ & It &  & 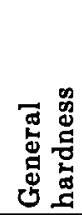 \\
\hline $\begin{array}{l}\text { Farafra, } \\
\text { spring }\end{array}$ & 6.46 & 0.4 & 0.2 & 2.5 & 0 & 1.3 & 1.1 & 1.7 & 215.6 & 1.7 \\
\hline $\begin{array}{l}\text { Farafra, } \\
\text { end of canal }\end{array}$ & 6.80 & 0.8 & 0 & 1.6 & 0 & 1.2 & 0.8 & 0.4 & 185.1 & 2.2 \\
\hline $\begin{array}{l}\text { Farafra, } \\
\text { saline marsh }\end{array}$ & 6.70 & 10.2 & 1.8 & 13.4 & 0 & 5.0 & 10.1 & 10.3 & 1816.8 & 33.6 \\
\hline Ain Haidia & 6.87 & 2.6 & 0.6 & 4.2 & 0 & 2.7 & 3.4 & 1.3 & 548.2 & 9.0 \\
\hline
\end{tabular}

It is, therefore, rather difficult to find out a general pattern of land utilization and the ensuing relationships in the standard oases. One can only note that generally:

- smaller parcels are to be found in the surroundings of the old well, on 
the grounds cultivated for a long time, which is certainly bound up with their multiple division by right and succession: the largest are the new fields on the outskirts;

- cultivation of plants has a more monocultural character in the central part; it is more diversified in the exterior, especially on the outskirts, where on the soils with the low salinity level there is experimental farming without the use of fertilizers.

Quite surprisingly, such attempts, which are apparent in many places (Fig. 3 ) are successful at least in the first years of cultivation. Contrary to these observations, in the opinion of Mr. B.Wicik, a soil specialist from Warsaw University, the soil at the outskirts of the oasis is practically of no agricultural value. These are mostly loamy sands, called locally turba hagariya (stony soil), slightly dusty, of pulverulent structure with a significant admixture of gravel grains and with vestigial particles of humus (below 0.1 per cent) and phosphorus, which are easily assimilable by plants. In relation to these arid soils, slightly carbonate $\left(6.78\right.$ per cent of $\mathrm{CaCO}_{3}$ in the analyzed sample), alkaline ( $\mathrm{pH}$ over 9), containing sodium in a state of sorptive complex, internal oasis soils, called turba tiniya (clayey soil), are much more wealthy with components essential for the plants' growing. They could be considered to be transformed by man's action but not to the level showing full characteristics of anthropic substance yet. So far, they have had no sufficient proportion of humus $(0.87$ per cent in the analyzed sample) and phosphorus. They constitute a medium-heavy loam, capable of absorbing moisture and fertilizers' components, chemically neutral, containing ca $50 \mathrm{mg} / 100 \mathrm{~g}_{2} \mathrm{O}_{5}$ and strongly carbonate (15 per cent $\mathrm{CaCO}_{3}$ ). They can be approximately classified as para-limestone soils and their neutral chemical reaction $(\mathrm{pH} 7.2)$ does not indicate contents of harmful components such as, for instance, sodium.

Typical agricultural models in the oasis are disturbed by the above-mentioned newly reclaimed fields not included as yet into the traditional system of land ownership and utilization. They are being purchased also by the newcomers from outside the oasis, which leads to conflicts with the local population. The process has, no doubt, a bearing on the acreage and number of parcels that make up a farm, also in the traditionally cultivated area.

Here is an example of an old farm (meant as a unit of a joint production and common consumption of its yields) cultivated by a multi-generation familial unit. Its oldest field with an area of only about $60 \mathrm{sq}$. m, situated just at the edge of the settled area (IV in Fig. 1) is overgrown by a date palm grove. Two other fields are watered by the old well: the smaller one (I in Fig. 1) with an area of about 900 sq.m is also in the majority planted with date palms, the bigger (II in Fig. 1) ca 4,000 sq. $\mathrm{m}$ is mainly planted with olive trees, but recently one can also find citrus trees (oranges, tangerines) in it. On the grounds irrigated by the new well, much more distant from the village, there is an orchard (III in Fig. 1) with an area of 
about 1,200 sq. $\mathrm{m}$ of various fruit trees. Young date palms are predominant (18), but there are also tangerines (11), figs (3), lemons, one olive tree, one apricot, a plum and an apple-tree. Besides, one can meet vine, sugar cane and clover. On the new, desalinated fields situated externally, outside the drains, the farm makes partial use of a large field ( $V$ in Fig. 1), ca 5,000 sq.m, where in addition to a few young trees such as date palms, olive trees, apple, tangerine trees and figs, various plants are grown, mainly cereals, vegetables and fodder crops such as wheat, maize, clover, beans, dill, tomatoes, onion, garlic, sunflower, sugar cane, banana, henna, gir-gir (kind of leaf-radish used for salad), and fodder spinach (hodar). The farm has thus about 1.2 ha of multi-purpose arable land under cultivation of which more than a half has been cultivated since the new well was put into service. More grounds (ca $2.5 \mathrm{ha}$ ) were acquired for a future use from the land newly reclaimed, but they have not been as yet put under cultivation. The farm's active holdings are supplemented by some domestic animals: 8 sheep, 3 goats, 2 donkeys and one camel.

Supposedly, the described farm is an average and standard one at Farafra and the majority of agricultural-productive units own 1,2 or 3 fields destined for market output with probable differentiation of dominant plants (date palms or olive trees), as well as 1 or 2 parcels variously planted with vegetable-grain-fruit bearing plants and very diversified.

The present transformations, in the first place investments in hydrology and the growing social and economic position of Qasr el-Farafra are reflected also in the condition of many ( 15 or so) small, ain-irrigated oases (Fig. 4 ) which are dispersed over an area surrounding it within a radius of some $10 \mathrm{~km}$ and much farther in the southerly direction. Only some of them, especially most distant ones, are permanently inhabited. An example may be a decaying Ain Tinin settled by two families only. But also a prosperous Ain Haidiya is inhabited only by two families, notwithstanding its intensive farming in the area of ca 2.5 ha divided into more than 100 parcels of average size $4 \times 3 \mathrm{~m}$, where date palms, olive trees, various vegetables (beans, onions, green pepper) and grains (barley, durum wheat) are grown on the ain-oasis borders. Fields are irrigated with the mediumhard chloride-sodium water, stronger mineralized than the water used at Qasr el-Farafra. Greater part of these tiny oases is cultivated by persons living at Qasr el-Farafra. The oases, once inhabited, are mostly deserted now, which is evidenced by the ruined farm buildings, as, for instance, at Ain Muffara, where the withering date palms are still supported by a qanat (underground irrigation channel), in Egypt called jip, supplying water from the distance of about $250 \mathrm{~m}$. However, only some of these ain-oases are definitely dead from the want of water (Ain Bigirra, Bir Dakkar). Most of them, although uninhabited, are effectively cultivated, especially where the water supplying investments were accomplished within the framework of the governmental projects. They even made it possible to create new ain- 
oases, particularly in the southern and south-western region. In this way, for instance, Ain Kifirein, situated in the vicinity of Qasr el-Farafra, is properly functioning and growing thanks to the new qanat built in 1990, which has replaced an older, already collapsed, tunnel. This one had shafts distant 20 to $40 \mathrm{~m}$ from each other reaching even as much as $75 \mathrm{~m}$. The new one is cemented and very well maintained. Its 49 shafts (Fig. 5), distant from 5 to $6 \mathrm{~m}$ from each other, cover a stretch of $280 \mathrm{~m}$ and lead to a $100 \mathrm{~m}$ long canal, roofed in the beginning and uncovered farther on. It supplies fields of cereals and vegetables with water and leads to the ain proper. Flow of water of some 80 cubic metres per day allows 6 farms to cultivate effectively about 5 ha of lands predominantly planted with olive trees, date palms, but also with occasional citrus trees, apricots and apple-trees. In their shade and on the borders, vegetables and wheat are grown.

All in all, Farafra appears to be a non-typical oasis or perhaps rather a typical one in non-typical environment, where water is in profusion and the traditional ways of management meet the modernized non-traditional methods of rural economy. 